\title{
Place Names in Ekegusii Language: A Cognitive Linguistics Approach
}

\author{
Aunga Solomon Onchoke \\ Kaimos Friends University College, Kenya \\ aungasolo@yahoo.com
}

\begin{abstract}
This paper analyses place names in the Ekegusii language from the cognitive linguistics point of view. The study is grounded on three objectives: to identify and explain the Ekegusii names of places, to describe the social cultural values, and to account for the cognitive processes involved in their mapping, analysis and elucidation. The data comprises of a list of Ekegusii place names collected from two counties, Kisii and Nyamira, by interviewing people through snowballing, and later holding a panel discussion with selected elders regarding the mapping processes and meanings associated with them. The Cognitive Metaphor Theory was used to map them to the different types of conceptual domains. Findings from this study show that place names in Ekegusii are conceptualized as seasons, topography, people, animals, plants and objects (as source domains which are social-culturally determined), and portray their cultural identity and tradition. The study concludes by suggesting further research in onomastics, especially on metaphor and metonymy in other languages of the world. Keywords: metaphor, cognitive linguistics, culture, onomastics, Ekegusii.
\end{abstract}

\section{INTRODUCTION}

This is a cognitive linguistics study of Ekegusii Onomastics dealing with the study of names of places (toponyms). It seeks to establish how language expresses cultural reality, and reflects the attitudes, beliefs and world outlooks of the people (Lakoff \& Johnson, 1980; Kövecses, 2005 \&2006) through the study of Ekegusii place names. The study focuses on Ekegusii names within Gusii land which covers two counties: Kisii and Nyamira (Ogechi, 2002). According to Guthrie (1964), Ekegusii, whose speakers are called Abagusii, is categorized into the zone E42 narrow East African Bantu language group, occupying the Southern section of the cool and fertile western highlands of Kenya. Kisii, which is their ethnic language, is also traditionally known as Ekegusii. The number of Ekegusii language speakers may not be known, but Ekegusii Language Native speakers (ELNS) are estimated to be about 4 million based on statistics provided by the Kenya National Bureau of Statistics (GoK, 2010). Most Ekegusii language speakers are multilingual, maybe because Kenya, where Abagusii are found, is a multi-lingual country with most of the people speaking more than one language (Ogechi, 2002). Ekegusii is classified as an agglutinating language due to its morphological behavior (Webb \& Kembo-Sure, 2000). Most words typically, consist of a basic root followed by one or more affixes. A typical feature of this language family is that nouns fall into noun classes. There are specific singular and plural prefixes for each noun class which also serve as markers of agreement between the subject and the verb. Moreover, the noun determines prefixes of all words that modify it, and the subject determines prefixes of other elements in the same verb phrase.

Some scholars have argued that in most parts of the world, place names have a variety of origins; some are transferred, some are borrowed, and many are descriptive coinages (Bright, 2003). This paper establishes how Abagusii conceptualize names of places as seasons, topography, people, animals, plants and objects, and how culture influences the choices of these names. This is in line with Bakhutiar (2013) who posited that proper names can be used figuratively, that is, both metaphorically and metonymically. Many other researchers have shown that there is a close interaction among language, culture and cognition; language preserves culture, impacts cognition by 
providing a system of aiding memory, and culture by entrenching culture-specific preferences for understanding of the environment (Grady, 2005; Takada, 2006; Kövecses, 2005). Similarly, Gleason (1961) postulates that language and culture are closely linked because language expresses one's way of life which is part of culture. Language is also used to show, regulate and convey culture. Language helps us express our thoughts, so, it is assumed that the Kisii place names are influenced by their thinking and the language which they use (Cooper, 1986). The importance of place names can be seen from a study carried by Zilliacus (1978), who says that place names are an important part of our social, geographical and cultural environments.

Place names in the Abagusii community form an integral part of understanding their culture. This is in tandem with Andersson (1994), who argued that place names, like other names, are part of human language. Names are used in a variety of functions, not only as expressions referring to particular people, animals and objects, but also as a way of communicating cognitively, emotionally, ideologically, and socially. Helleland (2012, p. 10) succinctly observes that place names may be said to represent the oldest living part of the human cultural heritage, in the sense that they have been handed down orally from generation to generation for hundreds or thousands of years at the place where they were coined. Therefore, it is important to note that place names form a special part of Abagusii cultural heritage in that they tell us something about the place to which they refer and about the name givers.

\section{THEORETICAL FOUNDATIONS: CONCEPTUAL METAPHOR THEORY}

This study is anchored in the tenets of Conceptual Metaphor which is also called Cognitive Metaphor Theory (CMT), first associated with Lakoff and Johnson (1980). Cognitive linguists have argued that people speak metaphorically because they reason, sense, behave, and act metaphorically, and that a metaphor is a property of thought and cognition. They said that, in analyzing a metaphor, there are inter-domain mappings of concepts in two different domains (source also called vehicle or $\mathrm{X}$ and the target also tenor or topic or $\mathrm{Y}$ ) and that the set of correspondences between them are called "conceptual metaphors". In CMT, we use imagination to map and understand experiences using metaphors or metonymies on the basis of image schemas with ${ }^{1}$ ontological correspondences between the domains (Lakoff and Johnson 1980). The source domain consists of a set of literal entities, attributes, properties, processes and relationships, linked semantically and stored in the mind (Gibbs, 1994; Langacker, 1999; Lakoff \& Johnson, 1980, 1987, 1999; Gibbs, 1994; Evans \& Green, 2006). This paper focuses on metaphor since one of the most important properties of metaphor is its ubiquity in language and thought. ${ }^{2}$ Jakel (2002) summarized the basic principles of the refined Cognitive Theory of Metaphor into nine hypotheses as put forward by different cognitive linguists, namely ubiquity, domain, model, diachrony, unidirectionality, invariance, necessity, creativity and focusing. These tenets are observed in this study.

This study is about metaphor in Abagusii culture; it is informed by other studies on the language like Aunga \& Wen (2017), Nyakoe et al. (2014) among others. Metaphorical language and culture is a topic that has been much discussed by many linguists. Among them is Kövecses (2005; 2006), who assert that some metaphors are culture specific and others are universal. Consequently, in trying to unravel the functions of metaphors in language cognition and culture, Ritchie (2013), identified and described the different types of metaphors. He argued that many primary metaphorical concepts are based on cultural specific experiences. This position had also been adopted by Lyons (1968), who contended that the language of a particular society is an important part of its culture, and that the term drawn by each language usually shows the culturally important features of animals, objects, plants, institutions,

\footnotetext{
${ }^{1}$ Ontological correspondences are the processes by which the source entities (people, objects, plants, actions or states are mapped onto their counterparts in the target domain.

${ }^{2}$ For detailed information on the nine principles of the refined cognitive metaphor read Jakel (2002).
} 
and other activities in the society in which the language operates. Similarly, Azuma (2012), Moon (2006) and Maalej (2004) who did research in African languages agree that cultural beliefs and practices affect the conceptualizations and interpretations of the metaphor. According to Bright (2003), the naming of places is a universal property but the ways of naming these places is culture specific.

With a view to bridging the research gap on the conceptualization of metaphors and culture, Takada et al. (2006) used the resemblance metaphor which they called "social- cultural metaphor" in analyzing how women are perceived in Japanese. This study further discusses the resemblance metaphors (Grady, 2005 \& Takada, 2006), in Ekegusii place names, an African Bantu language from a cognitive linguistics point of view. Therefore, we seek to discuss how metaphors reflect and structure our understanding of reality in relation to place names in Ekegusii.

\section{METHOD}

The paper adopted an iterative research design. This involved repeatedly returning to the source of the data (respondents and the discussion panel) to ensure that the understanding of the meanings of the names truly comes from the data (Creswell, 2012). In practice, this means a constant comparison of names and their meanings was conducted to guide the mapping processes in the subsequent panel discussions. This, in turn, meant that the study sought to describe a phenomenon that occurs naturally without the intervention of an experiment or artificially contrived treatment (Seligar and Shohamy, 1989).

The researcher collected the data (names of places) from Kisii and Nyamira towns (headquarters for the two counties), whereby the researcher interviewed respondents using an interview schedule. The respondents were identified through snowballing since the age of the respondents was a critical factor in this study. All the respondents were required to be 70 years and above in terms of age, born and brought up in Kisii highlands. 60 names and their corresponding meanings were obtained from the respondents.
The same names and their meanings were further subjected to a panel discussion of 10 elderly people (5 men and 5women). This small sample was chosen in order to allow for in-depth investigation and analysis of data (Trudgill, 1973).

The researcher, assisted by the research assistant, asked the panel questions about the names collected as he captured their explanations assisted by a video camera. They were further asked to name the contexts in which these names were given and explain the literal and implied meanings that some of these processes elicited. The panel discussion permitted a greater in-depth response which in turn gave an insight into the feelings, background, hidden motivation, intuitions, interests and decisions of the panelists about their culture (Mugenda \& Mugenda, 1999).

The data obtained was first presented in Ekegusii orthography, and later, a gloss in English provided through the processes of transcription and translation. The transcribed data were edited and counter-checked with the field notes in order to come up with a clean and organized copy to facilitate recall of information. The names that were collected were sorted out and classified into different categories by looking at the features that were related. A list of these categories was then compiled and patterns were identified. A list of 60 names was picked which had the salient features. Similarly, the images that the names revealed were explained, and the researcher showed how these names were viewed in Ekegusii society. Then the researcher went ahead to establish trends and relationships from the gathered information. The social-cultural values from the data on the cognitive processes were then mapped from $X$ to the $\mathrm{Y}$ domain, and then analyzed using the Cognitive Metaphor Theory.

\section{DISCUSSION AND INTERPRETATION OF THE FINDINGS}

Using the socio-cultural metaphor model, the study examines how names of places are conceptualized in Ekegusii and the mapping processes involved in this conceptualization. Data obtained from the respondents comprised of 60 names. The names were then classified into 6 
different themes/properties acting as the source Conceptual Metaphor Theory as presented in the domain in the mapping process using the table below.

Table. 1: Summary of names associated with places in Ekegusii and percentages

\begin{tabular}{|l|l|l|l|l|l|l|}
\hline $\begin{array}{l}\text { Areas } \\
\text { Mapped }\end{array}$ & $\begin{array}{l}\text { Surrounding( } \\
\text { terrain) }\end{array}$ & $\begin{array}{l}\text { Event \& } \\
\text { Season }\end{array}$ & People & Object & Plants & Animal \\
\hline $\begin{array}{l}\text { Number of } \\
\text { names }\end{array}$ & 12 & 10 & 10 & 8 & 15 & 5 \\
\hline$\%$ & 20 & 17 & 17 & 13 & 25 & 8 \\
\hline
\end{tabular}

Figure 1 summarizes the categories of the 60 Ekegusii names as collected from the respondents. There were 12 names based on terrain, 10 based on event and season, 10 based on people, 8 based on objects, 15 based on plants, and finally, 6 based on animals.

The data above shows that places in the Gusii region were named after animals, objects, plants, events or seasons, people and the terrain (the topography of the area). According to this study, these are source domains. This is in line with other scholars such as Zawawi (1998) who posited that a name of an individual is perceived as a hidden message that the name giver conveys to a particular society through the bearer of that name and that a name is like a document where one can read the, culture, beliefs, philosophy and history of the individual or the family or place in time and space. Further, Zawawi (1998) observed that personal names give very vital information of African cultural affiliations. He further argued that names convey, to those who know their origin and meaning, the social, political, religious and cultural experiences of the people who have created them. The same sentiments are echoed by Mutunda (2011) when he argues that in Africa, names convey a certain message to a society.

Most of these place names are metaphorical, and the respondents could not say when exactly the names came into existence as they are historical terms. Metaphors carry images, feelings, values, and thought patterns entrenched in our cultures (Mittelberg, 2007). Dirven, Wolf, Poltzenhagen \& Kövecses (2005) point out that a metaphor is not only based on similarity but on cross-domain correlations in our experience, which give rise to the conceptualized similarities between the two domains of the metaphor. These observations resonate well with names among the Abagusii community, where a name conjures meaning(s) and an image (s) at the same time.

According to this model which is within the resemblance metaphor, the source and target concepts are associated with socially defined properties as espoused by Grady (1999) and Takada et al. (2006). This means that both the values of the $X$ and $Y$ domains are defined by the people within a social setting. In this way, the source is mapped to the target because the properties defined are alike. Thus, specific qualities of the source or $\mathrm{X}$ domain (animals, objects, plants, events or seasons, people and the terrain (the topography of the area) as understood and perceived in Ekegusii culture, are mapped onto the target or $\mathrm{Y}$ domain (places).

\section{a. The Physical Topography is a Place}

Here, the physical topography is the $X$ domain and the actual name of a place is the $Y$ domain. Properties of $X$ are transferred to $Y$; hence, $Y$ is understood in terms of $X$. Abagusii people tended to name their places depending on the physical topography, that is, characteristics of what the area is like. This includes place names such as Kegoro and Egetunwa (A hill and a Mountain respectively). The two places had specific cultural significance to the Abagusii migration and settlement patterns. The respondents pointed out that the Abagusii people opted to settle in hilly and mountainous 
places for security reasons from their aggressive neighboring communities such as the Luo and Kipsigis. On the other hand, that they avoided settling on Ekerubo (A flat area), which was only used then for grazing cattle and enacting cultural rituals and festivals such as harvest rituals, although the situation has changed now. This explains why places like Nyabitunwa or Matunwa (a hilly area and a place with many hills respectively) are heavily inhabited. Places like Nyaboraire (a sleepy area) and Matongo (this is a gentle valley) were deemed as good for farming. These findings are in tandem with Dobric (2010) who concluded that the roots of certain names seem to be highly culturally conditioned being that they stem from local geographical areas, local gods or specific and different languages. On his part, Helleland (2012) posits that one can see geographical names as a reflection of the interplay between humans and nature through different periods of time. Thus, the lore that underlies the settlement patterns among the Abagusii is thus embedded in the reasoning behind the naming of various places that they settled.

\section{b. An Animal is a Place}

The name of an animal and its associated properties is the $X$ domain; the name of the place is $Y$ domain, so the target is perceived in terms of the source. Findings from this study show that a number of places among the Abagusii community shared names with animals. It is, therefore, common to encounter names such as Nyabioto (a place with many frogs). This was a waterlogged swampy area that was once infested with frogs. Despite the fact that the frogs are no longer there, the place still retains the name. The same applies to places like Nyaututu (a place with many owls), Bumburia (a place that had a lot mongoose), Nyangoye (a place that had many baboons), Masimba (a place that had many lions), and Gesusu (a place that had many hares). These places have maintained their names despite the fact that the animals they are named after are no longer there. This implies that place names are functioning as a cultural memory among the Abagusii. These findings concur with Helleland (2012) who quips that place names function as voices of the past, which in its turn may strengthen feelings of home. Thus place names can function as a textual representation of the historic landscape. In this regard, the later generations among the Abagusii will be able to connect to their historical past by listening to the stories that accompany these place names.

\section{c. An Event or Seasonis a Place}

A memorable event or season and its associated affiliations act as a source domain and the name of a place is the target domain. The name served as a permanent remembrance of the season or event. Among the Abagusii, places are named after major events or seasons that occurred in the region in the past. Such place names include Morembe (meaning 'peace'). This is a place at the border with the Maasai community where there used to be wars, so they called it Morembe to bring peace between the warring neighboring communities. The Abagusii community had once settled in the course of their migration in a place in neighboring Kericho County but the place was hostile as many people died there, and food crops did poorly. For purposes of remembrance, they called it Kabianga (they have refused), and moved on to settle the current place where they live. Implying that the major events were given names to remind the community of the event in future generations and, therefore, carry the history of the community. These findings confirm Helleland's (2012) argument that many place names are also identified with past events, and are pegged upon which stories can be told both written and oral.

\section{d. An Object is a Place}

The name of an object and its associated entities act as the source domain, and the name of a place is the target domain. Some names given to some areas suggest presence of certain objects. Names such as Magena (the stones; the places had many stones), Getare (the place had rocks), Egesieri (entrance; or; name given to the entrance to the town), Nyamache (a place full of water or swampy), Esani (this an area that had the shape of a plate or 
looks like a plate), and Nyabao or Kianyabao (The place had a lot of timber and furniture being sold).

\section{e. A Plant is a Place}

The name of a plant and its associated features act as the source domain, and the target domain is the name of a place. Places are conceptualized as plants. Common names identified are Metobo (the area had a lot of Sodom apple trees), Motonto (the area had a lot of bamboo sticks), Keumbu (the area was known for harvesting mushrooms), Nyaigesa (This is a place with bounteous harvests in whatever they grew, as it was a very fertile place), Kebabe or Kenyoro or Kiabonyoru (these are types of grasses for thatching Gusii traditional huts. The place had a lot of these types of grasses), Mobamba (an area where cotton was grown in plenty), and Kenyambi (an area full of couch grass).

\section{f. A Person is a Place}

A person's name is the $X$ domain and the name of a place is the $Y$ domain. These were names of people given to places. The names were given based on personal praises, occupation, attire, the length of stay at a place, peculiar utterances, mannerisms, or used as a landmark. An example is Riochanda means Ochanda's area, Borangi means Nyarangi's area who was a painter, Bwonyangi is Onyangi's area, Riasindani, is Sindani's area, Riosoya is Osoya's place and Riandoka is Andoka's place. The significance of the names of places representing names of prominent personalities in a community can be summed up by Tilley's (1994) argument that personal and cultural identity is bound up with the place; a typo-analysis is one exploring the creation of self-identity through a place. The geographical experience begins in places, reaches out to others through spaces, and creates landscapes or regions for human existence.

\section{CONCLUSION}

This study expounded on the social-cultural metaphor which is a distinction in resemblance metaphors where the source and target domains are social-culturally determined. It is clear from this study that metaphors are very important in the lexicon of Ekegusii onomastics, and form the basis by which we conceptualize place names in concrete terms (people, animals, objects, plants, events and topography of the area) with conceptual metaphors such as, PHYSICAL TOPOGRAPHY IS A PLACE, AN EVENT OR SEASON IS A PLACE, A PLANT IS A PLACE, AN ANIMAL IS A PLACE, AN OBJECT IS A PLACE and A PERSON IS A PLACE. Thus, a thorough understanding of Ekegusii language, history, events, beliefs, and their philosophy will enable easier comprehension of the metaphors used by the Abagusii people. The successful metaphor is a tool that allows the receiver to understand more frames of reference involved. The study has also established that metaphors are closely associated with the social-cultural settings of a people because they reflect and mark a people's culture and identity. Hence, the study concludes that metaphors unite reason and imagination, creating an imaginative reality to give an insight into everyday experiences of a united group of people

\section{REFERENCES}

Andersson, T. (1994). The existential conditions of place names. In Ulfsparre, G. (ed.),

Ortnamnvärdaattvårda.

FöredragfrånRiksantikvarieämbetetssymposium Ortnamnskultur. Stockholm 5-7 maj 1993, 7-21. Stockholm: Riksantikvarieämbetet.

Agyekum, K. (2006). The Sociolinguistic (sic) of Akan Personal Names. Nordic Journal of African Studies, 15(2), 206-235.

Akama, J. S., Maxon, R. (2006). Ethnography of the Gusii of Western Kenya: A Vanishing Cultural Heritage. The Edwin Mellen Press.

Akinnaso, N (1983). Yoruba Traditional names and the Transmission of Cultural Knowledge. Names, 31(3), 139-159.

Aristotle (1954). Rhetoric. (Trans. by Rhys Roberts). The Modern Library, Random House.

Aunga, S. O. \& Xu Wen. (2017). A cognitive analysis of woman metaphors in Ekegusii language. Linguistics and Literature Studies, 5, 344 - 353. doi: 10.13189/11s.2017.050503

Azuma, M. (2012). English Native Speakers' Interpretation of Culture-Bound Japanese Figurative Language. In MacArther F, et al. 
(eds). Metaphor in Use: Context, Culture and Communication. Amsterdam/Philadelphia: John Benjamins Vol. 38 pgs 50-80

Bakhtiar M. (2013). Creative Use of Proper Names in Persian. Fotvos Lorand University

Bosire, F.(1993). Dialects Rogoro and Maate. University of Nairobi Unpublished MA Thesis.

Bright W. (2003). What is a name? Reflections on onomastics. Language and linguistics, 4(4), 669681.

Chomsky, N. (1972). Language and Mind. Enlarged ed. Harcourt Brace Jovanovich, Inc.

Cooper, D. (1986). Metaphor. Oxford: Blackwell.

Coulson, S. (2007). Electrifying results: ERP data and cognitive linguistics. In M. Gonzalez-Marquez, I. Mittelberg, S. Coulson \& M. J. Spivey (eds.) Methods in Cognitive Linguistics. John Benjamins, 400-423.

Creswell, J. W. (2012). Qualitative inquiry and research design: Choosing among the five traditions (3rd ed.). Thousand Oaks

Dancygier, B. \& Sweetser, E. (2014). Figurative Language. Cambridge: CUP.

Dobric, N. (2010). Theory of names and Cognitive Linguistics-The case of the Metaphor. University of Klagenfurt Unpublished Ph.D Thesis.

Evans. V. \& Green. M. (2006). Cognitive Linguistics. An Introduction. University Press.

Fauconnier, G., \& Turner, M. (1998). Conceptual integration networks. Cognitive Science, 22(2), 133-187.

Fauconnier, G. (1999). Methods and Generalization. In: Cognitive Linguistics: Foundation, Scope and Methodology. Ed. by Th. Janssen andG. Redeker. Berlin. Pp. 95-124.

Geeraerts, D (1999). Beer and semantics. In Issues in Cognitive Linguistics, Leon De Stadler and Chris Eyrich, 35-55. Mouton de Gruyter.

Geeraerts Dirk, Stefan Grondelaers and Peter Bakema. (1994). The Structure of Lexical Variation. Meaning, naming, and context. Mouton de Gruyter.

Gries, Stefan Th. (2003). Multifactorial Analysis in Corpus Linguistics: A study of particle placement. Continuum Press.
Gibbs, R. W. (1994). The Poetics of Mind. Cambridge University Press.

Gibbs, R. W. ( 2007). Why cognitive linguists should care more about empirical methods. In M. Gonzalez-Marquez, I. Mittelberg, S. Coulson \& M. J. Spivey (eds.) Methods in Cognitive Linguistics. John Benjamins, 2-18.

Gladkova, A. (1999).The Semantics of Nicknames of the American Presidents. Australian National University.

Gleason, H. S. Jr., (1961). An Introduction to Descriptive Linguistics. Oxford and IBH Publishing Company

Grady, J. (1999). A typology of motivation for conceptual metaphor: correlation vs. resemblance, in R.Gibbs and G. Steen (eds.), Metaphor in Cognitive Linguistics. John Benjamins, pp. 79-100.

Grady, J. (1997). "Theories are buildings revisited," Cognitive Linguistics, 8-4, pp. 267-290.

Hiraga, M. (1993) Shoohintositenojosee: metafaanimirarerujoseekan. (Women as goods: views on women seen in metaphors), Nihongogaku, 5-12, pp. 213-233.

Guthrie, M. (1964). The classification of Bantu Languages. Dawson's Pall Mall Publishers.

Helleland B. (2012). Place Names and Identities. In Oslo Studies in Language 4(2). 95-116. (ISSN 1890-9639) http://www.journals.uio.no/osla

Kövecses, Z. (2006). Language, mind and culture: A practical introduction. Oxford University Press

Kövecses, Z. (2005). Metaphor in culture: Universality and variation. Cambridge University Press.

Lakoff, G. \& Johnson, M. (1980). Metaphors We Live By. The University of Chicago Press, completed with an Afterword in 2003.

Lakoff, G. \& Johnson, M.( 1999). Philosophy in the Flesh: The Embodied Mind and Its Challenge to Western Thought. New York: Basic Books.

Langacker, R. (1999). Grammar and Conceptualization. Berlin-New York: Mouton de Gruyter.

Lyons, R. J. (1968). Introduction to Theoretical Linguistics. New York: Cambridge University Press. 
Maalej, Z. (2004). “Figurative language in anger expressions in Tunisian Arabic: An extended view of embodiment". Metaphor and Symbol, $19,51-75$

Mac Cormac, E. R. (1985). A Cognitive Theory of Metaphor. Cambridge, Mass: The MIT Press.

Moran, R. (1997). Metaphor. In B. Hale \& C. Wright (eds.) A Companion to the Philosophy of Language. Blackwell, 48-268.

Mammadov A. (2013). Metaphors in the American and Russian Discourse. Azerbaijan: Azerbaijan University of Languages

Mutunda, S. (2011). Personal Names in Lunda Cultural Millieu. In International Journal of Innovative Interdisciplinary Research. University of Arizona. USA.

Ogechi, N. O. 2002. Trilingual Codeswitching in Kenya. Evidence from EkeGusii, Kiswahili, English and Sheng, Ph.D Dissertation, University of Hamburg

Quirk et al. (1985). Comprehensive Grammar of English Language. Longman.

Rosch, E. (1977). "Human Categorization". In N. Warren (ed.) Advances in Cross-Cultural Psychology 7. Academic Press, 1-72

Ritchie, D. (2013). Metaphor. Cambridge University Press
Rossi, P. (2001). Logic and the art of memory: The quest for a universal language. Translated and with an introduction by Stephen Clucas. Athlone Press.

Rouhi, M. (2011). Animal Metaphor in Cognitive Linguistics. Iran: David Publishing HouseSeliger \& Shohamy,(1990). Second Language Research Methods. New York: Oxford University PressTakada, M. et al. (2006). “A Study of Metaphorical Mapping Involving Socio-Cultural Values: How Woman is Conceptualized in Japanese". In Husby G, Sletton K. \&Michaelson (eds) Scandinavian Journal of Immunology: Scandanavia, 2, 394-404.

Tilley, C. (1994). A Phenomenology of Landscape. Places, Paths and Monuments. OxfordProvidence, USA: Berg.

Thomas, N. (1994). Detachable Women: Gender and Kinship in Process of Socioeconomic Change among the Gusii of Kenya. American Ethnologist, 21, 516-538.

Zawawi, S. M. (1998). African muslim names: Images and identities. Africa World Press.

Zilliacus, K. (1978). Place name care and place name planning. Proceedings from NORNA's Fifth Symposium in Hanaholmen 2325.9.1977]. NORNA-rapporter13. 